\title{
Genetic diversity among Polish landraces of common oat (Avena sativa L.)
}

\author{
M. Boczkowska $\cdot$ E. Tarczyk
}

Received: 10 October 2012/ Accepted: 25 February 2013/Published online: 28 March 2013

(C) The Author(s) 2013. This article is published with open access at Springerlink.com

\begin{abstract}
All over the world about 220,000 accessions of the genus Avena is preserved in gene banks. Polish oats collection, in the National Centre for Plant Genetic Resources, consists of about 2,500 accessions. More than $80 \%$ of them belong to the species Avena sativa. Only 136 accessions have the landrace or traditional cultivar status and 91 of them were collected in Poland. The main objective of this study was to estimate genetic diversity of a set of 67 Polish landraces using inter simple sequence repeat (ISSR) markers. We also tried to determine whether genetic diversity depended on the region and altitude of collection site and if there was a relationship between DNA polymorphism and some morphological traits. The accessions were collected between years 1973 and 1999 from areas of Northern, Southern and Eastern Poland. The obtained results indicated a relatively low diversity (0.09-0.37) of the common oat landraces. Analysis of molecular variation (AMOVA) showed that there were no significant differences within designated geographic regions. It indicated that at the same time the altitude of collection site had significant effect on the genetic differentiation of the accessions. AMOVA also showed the presence of variance between groups formed on the basis of the colour of lemma. White lemma accessions were also
\end{abstract}

M. Boczkowska $(\bowtie) \cdot$ E. Tarczyk

National Centre for Plant Genetic Resources,

Plant Breeding and Acclimatization Institute,

05-870 Radzików, Błonie, Poland

e-mail: maja.boczkowska@gmail.com characterized by highest genetic distinctiveness. Considering the evident impact of local climatic conditions on the genetic distinctiveness of Polish landraces utility of them in the Polish breeding programs should be considered.

Keywords Avena sativa - Genetic diversity · Germplasm · Landraces · Oat

\section{Introduction}

Oat is listed among the major cereal crops in the world. It is ranked sixth after wheat, maize, rice, barley and sorghum. The oat grain is a major livestock feed. It is also used widely for human consumption, as a source of valuable nutrients. During the last fifty years global production of oats decreased by $50 \%$. Therefore, conservation of Avena genetic resources has become important for mankind food security.

The main objective of genetic resources conservation is to preserve all existing diversity of a given crop gene pool without any changes in their genetic makeup. Another aspect of gene bank activity is studying, describing, and documenting the existing collection, and making this information available to scientists and other users. The effectiveness of gene bank activities is directly proportional to the amount of available information on the variability of particular species.

Molecular markers have been proved to be important and effective tool in the characterization and 
evaluation of genetic resources. They provide valuable information about the genetic variation both within and among species and populations in key areas of ex situ and in situ germplasm conservation. Currently, DNA markers are routinely used to evaluate genetic diversity of accessions in the gene bank collections. There are various types of molecular markers used for germplasm characterization, but each of them has several pros and cons. As so far an ideal marker does not exist. There are at least ten important systems of molecular markers used for genetic diversity evaluation. One of them is Inter Simple Sequence Repeat (ISSR), which is based on variation in the DNA regions between microsatellites. This technique involves PCR amplification of DNA fragments located between two adjacent, identical microsatellites with opposite orientation. The microsatellite sequence is used as a single primer in PCR reaction to amplify multiple fragments of different size randomly distributed throughout the genome (Zietkiewicz et al. 1994). The primers are usually between 16 and 25 bp long and could either be anchored at $3^{\prime}$ or $5^{\prime}$ end or also unanchored (Gupta et al. 1994; Meyer et al. 1993; Wu et al. 1994; Zietkiewicz et al. 1994). The main advantages of ISSR are: no need for any prior knowledge of genome sequence, low operational cost, low labor-intensity, high stability and reproducibility, and abundance of genomic information (Moreno et al. 1998; Shen et al. 2006). The main drawback is that ISSRs are inherited mostly as dominant genetic markers in a simple Mendelian fashion and high probability exists that the similar sized fragments are not homologous (Gupta et al. 1994; Tsumura et al. 1996).

ISSR were successfully used to study the genetic diversity in rice (Blair et al. 1999; Virk et al. 2000), sorghum (Medraoui et al. 2007), wheat (Sofalian et al. 2008; Pujar et al. 2002), barley (Fernández et al. 2002) and wild barley (Tanyolac 2003).

The main objective of this study was to estimate genetic diversity of a set of Polish oat landraces using ISSR markers. We also tried to determine whether genetic diversity depended on collection site and if there was a relationship between DNA polymorphism and some morphological traits. Results presented here are the direct continuation of the studies carried out by Nowosielska and Nowosielski (2008). They investigated the diversity of Polish oat landraces and cultivars based on morphological traits and DNA polymorphisms detected with AFLP markers.

\section{Materials and methods}

Plant material and description of collection site

The plant material consisted of 67 spring growth Polish oat landraces from the Avena collection of National Center for Plant Genetic Resources located in Radzików. The accessions were collected between years 1973 and 1999 from areas of Northern, Southern and Eastern Poland (Table 1). Collection sites have been marked on the contour map of Poland (Fig. 1). Botanical diversity of these accessions has been clearly described during the previous research (Nowosielska 2006). They were identified as seven botanical varieties (aristata Krause, aurea Körn., cinerea Körn., flava Körn., grisea Körn., krausei Körn., mutica Alef.) according to the classification by Rodionova et al. (1994). An overview of particular botanical varieties observed in the collection of landraces has been included in Table 2. Within each landrace from one to four varieties were recorded. Of the 67 accessions 24 were made up by one botanical variety, 38 by two botanical varieties, three by three botanical varieties and two by four botanical varieties. This shows the intra accessions heterogeneity of the material (Table 1). Within the collection of oat landraces botanical varieties occurred with the following frequencies: var. aurea in 44 accessions, var. mutica in 22 accessions, var. krausei in 20 accessions, var. aristata in 13 accessions, var. flava in 12 accessions, var. grisea in four accessions and var. cinera in two accessions. The majority of the analyzed accessions had yellow lemma (approximately $66 \%$ ). Among them, 15 were homogeneous as the variety aurea, and six as flava. Almost half of the accessions with yellow lemma were a mixture of two or even three varieties. White lemma was observed in 13 accessions among the investigated germplasm collection. Only one landrace had seeds with gray color of lemma. Six were mixtures of white and yellow or white and gray lemma seeds. Four botanical varieties were found in each of the accessions 51616 and 52351. The analyzed set of landraces included plants with two types of panicle i.e. uni- and equilateral. The vast majority $(82 \%)$ of the accessions was characterized by a unilateral panicle, seven landraces had the equilateral type, whereas, in five both types were intermixed. The presence or absence of awn occurred in the evaluated accessions in equal proportions, but it 
Table 1 Description of accessions used in the study and their collection sites

\begin{tabular}{|c|c|c|c|c|c|c|}
\hline \multirow[t]{2}{*}{ Accession number } & \multirow[t]{2}{*}{ Botanical variety } & \multirow[t]{2}{*}{ Acquisition date } & \multicolumn{4}{|c|}{ Collection site } \\
\hline & & & Latitude & Longitude & Altitude & Region \\
\hline 50079 & 7,1 & 1982 & $4924 \mathrm{~N}$ & $2001 \mathrm{E}$ & 718 & M \\
\hline 50338 & 4 & 1976 & $4931 \mathrm{~N}$ & $2209 \mathrm{E}$ & 386 & SE \\
\hline 50345 & 6,2 & 1978 & $5018 \mathrm{~N}$ & $2145 \mathrm{E}$ & 209 & SE \\
\hline 50381 & 4 & 1978 & $5018 \mathrm{~N}$ & $2145 \mathrm{E}$ & 209 & SE \\
\hline 50411 & 7,1 & 1974 & $5027 \mathrm{~N}$ & $2317 \mathrm{E}$ & 308 & SE \\
\hline 50432 & 7,1 & 1976 & $4924 \mathrm{~N}$ & $2018 \mathrm{E}$ & 578 & M \\
\hline 50438 & 2 & 1974 & $5040 \mathrm{~N}$ & $2310 \mathrm{E}$ & 226 & SE \\
\hline 50503 & 2,6 & 1973 & $5044 \mathrm{~N}$ & $2315 \mathrm{E}$ & 210 & SE \\
\hline 50512 & 7 & 1978 & $4930 \mathrm{~N}$ & $2014 \mathrm{E}$ & 783 & M \\
\hline 50520 & 2,4 & 1973 & $5216 \mathrm{~N}$ & $2219 \mathrm{E}$ & 150 & $\mathrm{E}$ \\
\hline 50521 & 2,4 & 1978 & $4933 N$ & $2059 \mathrm{E}$ & 461 & M \\
\hline 50524 & 6,2 & 1978 & $4932 \mathrm{~N}$ & $2206 \mathrm{E}$ & 342 & SE \\
\hline 50528 & 1,7 & 1976 & $4929 \mathrm{~N}$ & $2004 \mathrm{E}$ & 440 & SE \\
\hline 50529 & 4 & 1979 & $5338 \mathrm{~N}$ & 23 09E & 145 & $\mathrm{~N}$ \\
\hline 50530 & 7,1 & 1973 & $5044 \mathrm{~N}$ & $2315 \mathrm{E}$ & 210 & SE \\
\hline 50531 & $2,6,4$ & 1979 & $5301 \mathrm{~N}$ & $2321 \mathrm{E}$ & 155 & $\mathrm{~N}$ \\
\hline 50554 & 2,6 & 1973 & $4932 \mathrm{~N}$ & $2102 \mathrm{E}$ & 473 & M \\
\hline 50556 & 7 & 1978 & $4930 \mathrm{~N}$ & $2014 \mathrm{E}$ & 783 & $\mathrm{M}$ \\
\hline 50561 & 2 & 1973 & $5216 \mathrm{~N}$ & $2219 \mathrm{E}$ & 150 & $\mathrm{E}$ \\
\hline 50587 & 2,6 & 1973 & $5115 \mathrm{~N}$ & $2234 \mathrm{E}$ & 185 & SE \\
\hline 50593 & 7,1 & 1978 & $4930 \mathrm{~N}$ & $2014 \mathrm{E}$ & 783 & $\mathrm{M}$ \\
\hline 50613 & 5,3 & 1977 & $5039 \mathrm{~N}$ & $2154 \mathrm{E}$ & 192 & SE \\
\hline 50616 & 2 & 1976 & $4935 \mathrm{~N}$ & $2028 \mathrm{E}$ & 516 & $\mathrm{M}$ \\
\hline 50622 & 2 & 1978 & $4936 \mathrm{~N}$ & $2103 \mathrm{E}$ & 409 & $\mathrm{M}$ \\
\hline 50627 & 7,5 & 1977 & $5215 \mathrm{~N}$ & $2153 \mathrm{E}$ & 162 & $\mathrm{E}$ \\
\hline 50673 & 2,6 & 1974 & $5033 \mathrm{~N}$ & $2336 \mathrm{E}$ & 222 & SE \\
\hline 50694 & 2,4 & 1976 & 49 27N & $2220 \mathrm{E}$ & 394 & $\mathrm{M}$ \\
\hline 50698 & 2,6 & 1977 & $5049 \mathrm{~N}$ & $2219 \mathrm{E}$ & 269 & M \\
\hline 50705 & 2,6 & 1976 & $4924 \mathrm{~N}$ & $2018 \mathrm{E}$ & 578 & M \\
\hline 50706 & 2,6 & 1976 & $4924 \mathrm{~N}$ & $2018 \mathrm{E}$ & 578 & M \\
\hline 50709 & 2 & 1978 & $4948 \mathrm{~N}$ & $2154 \mathrm{E}$ & 309 & M \\
\hline 50712 & 2 & 1977 & $5022 \mathrm{~N}$ & $2150 \mathrm{E}$ & 192 & SE \\
\hline 50718 & 2,6 & 1974 & $5102 \mathrm{~N}$ & $2300 \mathrm{E}$ & 212 & SE \\
\hline 50725 & 2 & 1976 & $4923 \mathrm{~N}$ & $2008 \mathrm{E}$ & 785 & $\mathrm{M}$ \\
\hline 50754 & 2 & 1976 & $4930 \mathrm{~N}$ & $2030 \mathrm{E}$ & 583 & $\mathrm{M}$ \\
\hline 50758 & 4 & 1979 & $5420 \mathrm{~N}$ & $2256 \mathrm{E}$ & 183 & $\mathrm{~N}$ \\
\hline 50760 & 2 & 1977 & $5039 \mathrm{~N}$ & $2218 \mathrm{E}$ & 183 & SE \\
\hline 50902 & 2,6 & 1978 & $4922 \mathrm{~N}$ & $2011 \mathrm{E}$ & 880 & M \\
\hline 50904 & 2 & 1978 & $4922 \mathrm{~N}$ & $2011 \mathrm{E}$ & 880 & $\mathrm{M}$ \\
\hline 50925 & 4 & 1978 & $4930 \mathrm{~N}$ & $2024 \mathrm{E}$ & 535 & M \\
\hline 50945 & 2 & 1978 & $4922 \mathrm{~N}$ & $2011 \mathrm{E}$ & 880 & M \\
\hline 51519 & 2 & 1984 & $5203 \mathrm{~N}$ & $2218 \mathrm{E}$ & 159 & $\mathrm{E}$ \\
\hline 51521 & 4 & 1984 & $5150 \mathrm{~N}$ & $2229 \mathrm{E}$ & 155 & $\mathrm{E}$ \\
\hline
\end{tabular}


Table 1 continued

\begin{tabular}{|c|c|c|c|c|c|c|}
\hline \multirow[t]{2}{*}{ Accession number } & \multirow[t]{2}{*}{ Botanical variety } & \multirow[t]{2}{*}{ Acquisition date } & \multicolumn{4}{|c|}{ Collection site } \\
\hline & & & Latitude & Longitude & Altitude & Region \\
\hline 51522 & 4 & 1984 & $5107 \mathrm{~N}$ & $2320 \mathrm{E}$ & 233 & $\mathrm{E}$ \\
\hline 51599 & 2 & 1985 & $5052 \mathrm{~N}$ & $2304 \mathrm{E}$ & 217 & SE \\
\hline 51600 & 1,7 & 1986 & $5010 \mathrm{~N}$ & $2236 \mathrm{E}$ & 175 & SE \\
\hline 51603 & $7,1,2$ & 1986 & $5000 \mathrm{~N}$ & $2240 \mathrm{E}$ & 224 & SE \\
\hline 51604 & 7,1 & 1986 & $4941 \mathrm{~N}$ & $2229 \mathrm{E}$ & 335 & M \\
\hline 51605 & 1,7 & 1986 & $4941 \mathrm{~N}$ & $2231 \mathrm{E}$ & 393 & M \\
\hline 51606 & 2,6 & 1986 & $5224 \mathrm{~N}$ & $1947 \mathrm{E}$ & 100 & SE \\
\hline 51607 & 7,1 & 1986 & $5000 \mathrm{~N}$ & $2235 \mathrm{E}$ & 237 & M \\
\hline 51610 & 2,6 & 1986 & $5003 \mathrm{~N}$ & $2234 \mathrm{E}$ & 212 & M \\
\hline 51611 & 2 & 1986 & $5001 \mathrm{~N}$ & $2238 \mathrm{E}$ & 217 & M \\
\hline 51612 & 4,2 & 1987 & $5032 \mathrm{~N}$ & $2336 \mathrm{E}$ & 228 & $\mathrm{E}$ \\
\hline 51614 & 2,6 & 1985 & $5037 \mathrm{~N}$ & $2259 \mathrm{E}$ & 245 & $\mathrm{SE}$ \\
\hline 51615 & 6,2 & 1985 & $5051 \mathrm{~N}$ & $2326 \mathrm{E}$ & 245 & SE \\
\hline 51616 & $7,1,2,5$ & 1987 & $4921 \mathrm{~N}$ & $2012 \mathrm{E}$ & 913 & M \\
\hline 51617 & 2,7 & 1987 & $4922 \mathrm{~N}$ & $2011 \mathrm{E}$ & 880 & M \\
\hline 51618 & $2,7,6$ & 1987 & $4922 \mathrm{~N}$ & $2011 \mathrm{E}$ & 880 & M \\
\hline 51619 & 7,2 & 1987 & $4922 \mathrm{~N}$ & $2011 \mathrm{E}$ & 880 & M \\
\hline 52191 & 7,2 & 1997 & $4921 \mathrm{~N}$ & $2012 \mathrm{E}$ & 913 & M \\
\hline 52265 & 2,6 & 1997 & $4945 \mathrm{~N}$ & $1916 \mathrm{E}$ & 576 & M \\
\hline 52306 & 2,6 & 1998 & $5048 \mathrm{~N}$ & $2314 \mathrm{E}$ & 231 & SE \\
\hline 52338 & 2,6 & 1999 & $5026 \mathrm{~N}$ & $2026 \mathrm{E}$ & 285 & SE \\
\hline 52343 & 7,2 & 1999 & $5254 \mathrm{~N}$ & $2252 \mathrm{E}$ & 134 & $\mathrm{~N}$ \\
\hline 52344 & 7 & 1999 & $4930 \mathrm{~N}$ & $1945 \mathrm{E}$ & 729 & M \\
\hline 52351 & $7,1,5,3$ & 1999 & $5301 \mathrm{~N}$ & $2250 \mathrm{E}$ & 129 & $\mathrm{~N}$ \\
\hline
\end{tabular}

Botanical variety: 1 , aristata; 2 , aurea; 3 , cinerea; 4, flava; 5, grisea; 6 , krausei; 7 , mutica; Region: $M$ mountain; $E$ East; $S E$ SouthEast; $N$ North

should be noted that the ratio of individuals within landrace, which had awn was variable but it never has been equal to $100 \%$ (Nowosielska 2006).

All studied accessions had a set of geographical data describing the location of seed sample collection site: longitude, latitude and altitude (Table 1). On this basis, for each location characteristics of the environmental conditions i.e. an average annual temperature and mean annual amount of precipitation were determined (Nowosielska 2006).

DNA extraction and PCR procedure

Each accession was represented by one bulk of 25 randomly chosen individual plants. Equal amounts of young, healthy leaf tissue of each bulk was lyophilized, ground in beads mill and kept at $-20{ }^{\circ} \mathrm{C}$. Total genomic DNA was extracted by Genomic Mini AX Plant (A \& A Biotechnology) kit. DNA quality was evaluated by electrophoresis on $1.5 \%$ (w/v) agarose gel and its concentration was determined spectrometrically (NanoDrop Spectrophotometer ND-1000).

PCR amplification was carried out in a $10 \mu \mathrm{l}$ volume of a mixture containing $25 \mathrm{ng}$ of genomic DNA, $1 \mu$ SuperHotStart Taq polymerase (Bioron), 1x Taq buffer, $1.9 \mathrm{mM} \mathrm{MgCl}_{2}, 0.2 \mathrm{mM}$ dNTP's mix and $1.5 \mu \mathrm{M}$ primer. PCR amplification was performed in a thermocycler Verity 96 Thermal Cycler (Applied Biosystems) under the following temperature profile: $5 \mathrm{~min}$ at $94{ }^{\circ} \mathrm{C}$ followed by 45 cycles, each one included $30 \mathrm{~s}$ at $94{ }^{\circ} \mathrm{C}, 45 \mathrm{~s}$ at 58 or $54{ }^{\circ} \mathrm{C}, 2 \mathrm{~min}$ at $72{ }^{\circ} \mathrm{C}$ and the final extension for $10 \mathrm{~min}$ at $72{ }^{\circ} \mathrm{C}$.

Based on preliminary experiments a set of 8 ISSR di-nucleotide sequence primers anchored at $5^{\prime}$ or $3^{\prime}$ 
Fig. 1 Geographical distribution of collection sites of oat landraces in the territory of Poland

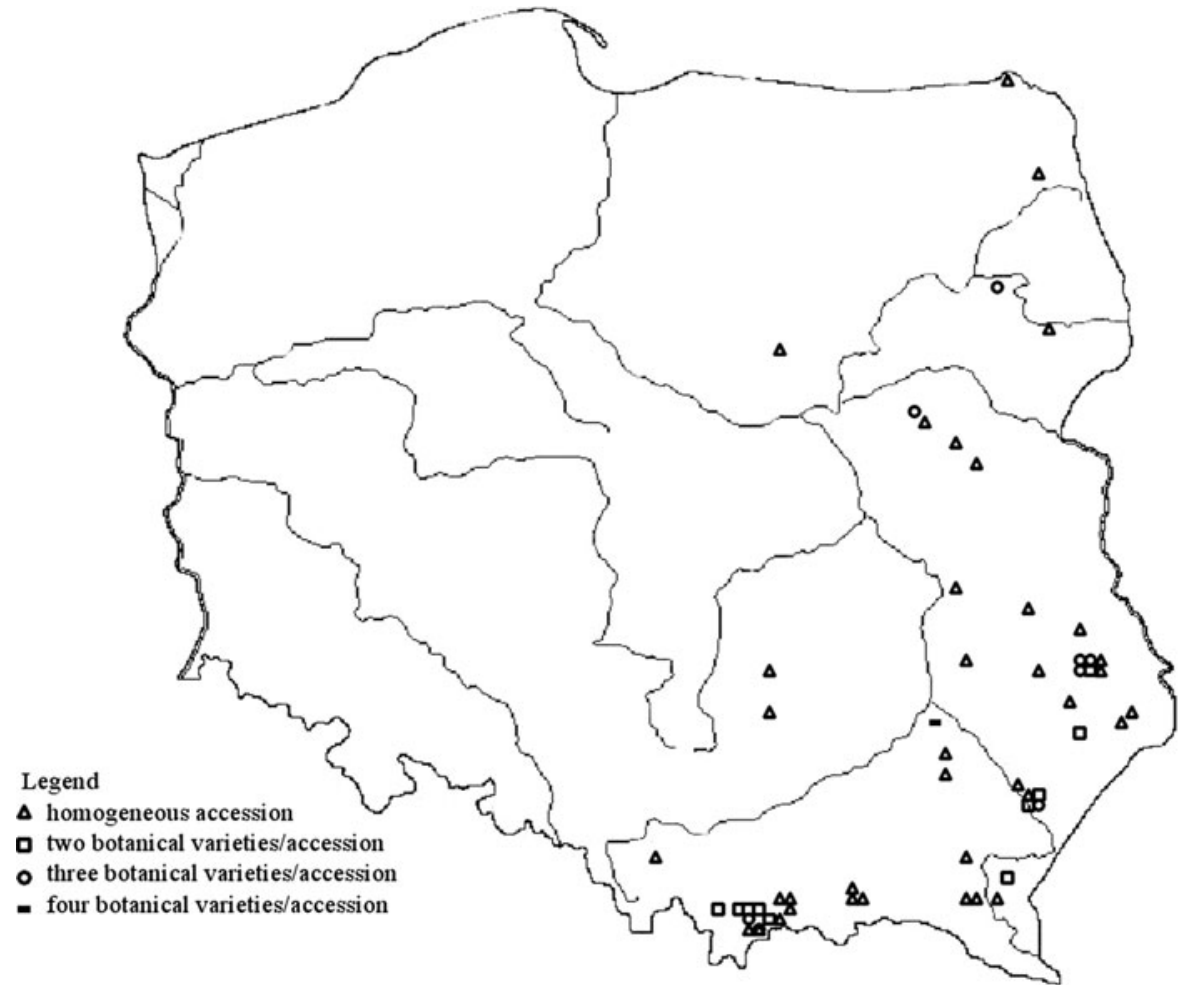

Data analysis

Table 2 Morphological traits of particular botanical varieties of A. sativa (Loskutov 2013)

\begin{tabular}{llll}
\hline Botanical variety & Panicle type & Awns & Colour of lemma \\
\hline aristata & Equilateral & Yes & White \\
aurea & Equilateral & No & Yellow \\
cinerea & Equilateral & Yes & Grey \\
flava & Unilateral & No & Yellow \\
grisea & Equilateral & No & Grey \\
krausei & Equilateral & Yes & Yellow \\
mutica & Equilateral & No & White \\
\hline & & &
\end{tabular}

end (University of British Columbia) were found to be sufficiently polymorphic to be used for the assessment (Table 3). Each of them was labeled at the $5^{\prime}$ end with one of the fluorochromes: 6-FAM, VIC, NED or PET (Applied Biosystem). The amplified products were separated and visualized using the capillary sequencer ABI 3130xl Genetic Analyzer. The $36 \mathrm{~cm}$ capillaries array filled with polymer POP-7 was used. The length of fragments was assessed against the standard size GeneScan1200 LIZ Size Standard (Applied Biosystems).
The length of the analyzed fragments was determined using GeneMapper (Applied Biosystems) software. The amplified fragments from each accession were transformed into binary character matrix where the presence of each reproducible fragment of defined length was scored as 1 , while its absence as 0 . The marker informativeness was measured by counting: TNF-total number of fragments, NPF-number of polymorphic fragments, NMF-number of monomorphic fragments, NUF-number of unique fragments. The Polymorphic Information Content (PIC) for each marker was calculated using the formula described by Roldan-Ruiz et al. (2000).

Genetic similarity for each pair of accessions was estimated according to Dice (1945), Jaccard (1908) and simple matching coefficients in FAMD 1.25 (Schlüter and Harris 2006). For the resulting matrices the Pearson's correlation analysis was performed. The distance transformation (distance $=1-$ similarity) was applied to the similarity matrix before using it for cluster analysis, which was used to examine the similarities between the studied accessions. It was 
Table 3 Summary on amplified DNA fragments generated by each primer

\begin{tabular}{|c|c|c|c|c|c|c|c|c|c|c|}
\hline \multirow[t]{2}{*}{ Primer } & \multirow[t]{2}{*}{ Sequence } & \multirow[t]{2}{*}{ Dye } & \multicolumn{2}{|l|}{$\operatorname{Tm}{ }^{\circ} \mathrm{C}$} & \multirow[t]{2}{*}{$\% \mathrm{GC}$} & \multicolumn{5}{|c|}{ Amplified DNA fragments } \\
\hline & & & Theoretical & Optimal & & $\mathrm{TNF}^{\mathrm{a}}$ & $\mathrm{NPF}^{\mathrm{b}}$ & $\mathrm{NMF}^{\mathrm{c}}$ & $\mathrm{NUF}^{\mathrm{d}}$ & PIC \\
\hline UBC 807 & $(\mathrm{AG}) 8 \mathrm{~T}$ & 6-FAM & 44.6 & 58 & 47.1 & 94 & 59 & 21 & 14 & 0.21 \\
\hline UBC 825 & $(\mathrm{AC}) 8 \mathrm{~T}$ & 6-FAM & 44.6 & 58 & 47.1 & 109 & 58 & 30 & 21 & 0.18 \\
\hline UBC 834 & $(\mathrm{AG}) 8 \mathrm{YT}$ & VIC & $45.8-48.0$ & 54 & $44.4-50.0$ & 124 & 77 & 29 & 18 & 0.20 \\
\hline UBC 841 & (GA)8YC & VIC & $48.0-50.3$ & 54 & $50.0-55.6$ & 122 & 73 & 36 & 13 & 0.22 \\
\hline UBC 856 & $(\mathrm{AC}) 8 \mathrm{YA}$ & NED & $45.8-48.0$ & 54 & $44.4-50.0$ & 104 & 71 & 15 & 18 & 0.23 \\
\hline UBC 857 & $(\mathrm{AC}) 8 \mathrm{YG}$ & NED & $48.0-50.3$ & 54 & $50.0-55.6$ & 79 & 35 & 9 & 35 & 0.17 \\
\hline UBC884 & $\mathrm{HBH}(\mathrm{AG}) 7$ & PET & $42.2-49.5$ & 54 & $41.2-58.9$ & 115 & 73 & 21 & 21 & 0.21 \\
\hline \multirow[t]{3}{*}{ UBC 885} & $\mathrm{BHB}(\mathrm{GA}) 7$ & PET & $42.2-49.6$ & 54 & $41.2-58.9$ & 148 & 85 & 44 & 19 & 0.19 \\
\hline & & & & & Sum & 895 & 531 & 205 & 159 & - \\
\hline & & & & & Mean & 112 & 66 & 26 & 20 & 0.20 \\
\hline
\end{tabular}

Single-letter abbreviations for mixed base positions: $\mathrm{Y}=(\mathrm{C}, \mathrm{T})$; $\mathrm{B}=\operatorname{not} \mathrm{A}$ (i.e. $\mathrm{C}, \mathrm{G}$ or $\mathrm{T}$ ); $\mathrm{H}=$ not $\mathrm{G}$ (i.e. $\mathrm{A}, \mathrm{C}$ or $\mathrm{T}$ )

a Total number of fragments

b Number of polymorphic fragments

c Number of monomorphic fragments

d Number of unique fragments

used to divide the data set into subsets in which the closest to each other accessions were placed together. The collected data were grouped using the UPGMA (Unweighted Pair Group Method with Arithmetic Mean) method of clustering. Results of the analysis were presented as a dendrogram. The UPGMA tree was visualized with TreeView 1.6.6 software (Page 1996). On the basis of the same matrix Principal Coordinate Analysis (PCoA) was performed by GenAlex6.2 (Peakall and Smouse 2006). This multivariate technique allowed us to find and plot the major pattern within multiple loci data set. The resulting distance matrix was also subjected to Analysis of Molecular Variance (AMOVA) using again GenAlex6.2. AMOVA estimated and partitioned total molecular variance within and between groups of accessions and then tested the significance of partitioned variance components using non-parametric permutational testing procedures with 999 permutations (Excoffier et al. 1992). The ФРT coefficient, which is analogous to Fst for binary data was calculated. For AMOVA analysis groups were determined on the basis of geographical regions, altitude, precipitation, temperature, lemma's color and panicle architecture.

Based on geographic coordinates of collection sites the matrix of geographic distance was generated. Correlation between geographical and genetic distances between samples was tested by Mantel tests with 999 permutations (Mantel 1967), using the GenAlex6.2 software. This is a nonparametric test examining relationships between two distance matrices which describe the same entity. The null hypothesis of this test implies lack of correlation between matrices. A similar analysis was conducted to compare the genetic distance and absolute difference in altitude, precipitation and temperature.

The hypothesis that there is a tendency for accessions to be more heterogeneous in certain location was verified using the $\chi^{2}$ test.

\section{Results}

Marker informativeness

A total of 895 scorable and reproducible ISSR fragments were generated using eight primers. The total number of amplified fragments (TNF) per primer ranged from 79 (UBC857) to 148 (UBC885) with an average 112 fragments per primer (Table 3). Out of 895 amplified fragments, 531(59.3\%) were polymorphic (NPF), $204(22.8 \%)$ were monomorphic at the level $p=0.05$ (NMF), and $159(17.8 \%)$ were unique (NUF). The average number of polymorphic 
fragments for a primer was 66, with maximum value 85 for UBC 885 and minimum 35 for UBC 857 . The percentage of polymorphic fragments across a primer ranged from $44.3 \%$ (UBC857) to $68.3 \%$ (UBC856). There was no significant difference between the primers anchored at the $5^{\prime}$ and $3^{\prime}$ end, neither in the total amount of amplified fragments nor in the polymorphic ones $(p=0.05)$. The set of ISSR primers used in this study generated 143 highly informative loci (data not shown) with PIC value greater than 0.45 , which represented $27 \%$ of polymorphic loci (NPF). The average PIC for the particular marker ranged from 0.17 (UBC857) to 0.23 (UBC856) with the mean 0.20.
Genetic similarity and clustering analysis

The data were computed to estimated genetic similarity among studied accessions based on Dice's, Jaccard's and simple matching coefficients. Strong, positive correlation between the matrices obtained by these three coefficients was observed. Most of the authors who described genetic variability of oats had chosen the Dice's coefficient to analyze their data. Due to this, the Dice was selected for further statistical analysis, to make our results comparable to bibliography. The resulting matrix (data not shown) exhibited similarity with the range $0.63-0.91$, and strongly
Fig. 2 Dendrogram clustering of 67 oat landraces based on the Dice dissimilarity index calculated using ISSR data. The color of the square placed next to the accession number indicates color of lemma (black-yellow lemma; white-white lemma; grey-grey lemma). Abbreviations used in figure (botanical variety:

1-aristata, 2-aurea,

3-cinerea, 4-flava, 5-grisea, 6-krausei, 7-mutica)

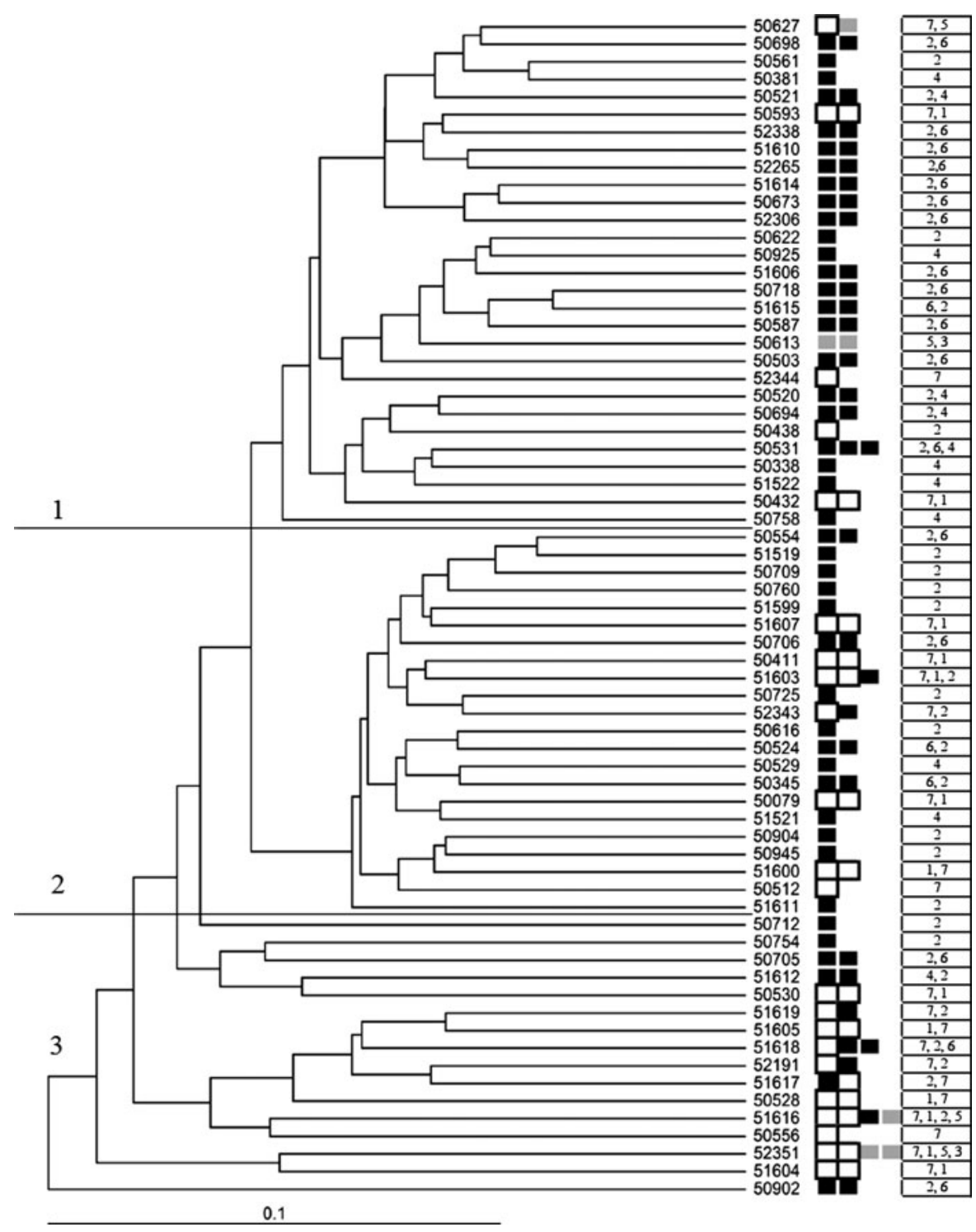


Table 4 Results of the pairwise Mantel tests

\begin{tabular}{lll}
\hline & $\mathrm{r}$ & $p$ \\
\hline Genetic versus geographic distance & 0.029 & 0.275 \\
Genetic distance versus altitude & $\mathbf{0 . 2 4 0}$ & $\mathbf{0 . 0 0 1}$ \\
Genetic distance versus precipitation & $\mathbf{0 . 1 7 0}$ & $\mathbf{0 . 0 0 1}$ \\
Genetic distance versus temperature & $\mathbf{0 . 2 5 8}$ & $\mathbf{0 . 0 0 1}$ \\
\hline
\end{tabular}

For details of the different distance matrices tested see text

Significant results $(p<0.05)$ are in bold type

supported rather small degree of genetic diversity in this germplasm collection at the DNA level. The minimum value $(0.63)$ was observed between the accessions 50556 and 50432, the maximum coefficient value (0.91) was observed between the 50718 and 51615 accessions. Both of these values suggested the high degree of similarities between all of studied accessions. However, a number of ISSR's that were amplified allowed distinguishing even closely related accessions from each other.

On the basis of the symmetrical distance matrix, which was obtained by transformation of similarity matrix, UPGMA clustering of accessions was performed. Next, based on the results, a cluster tree was plotted (Fig. 2), in which two clusters were clearly distinguished. They were composed of 29 and 22 accessions. The bottom part of dendrogram contained the group of accessions with lower affinity. The dendrogram indicated also the close relationship between pairs of accessions 50718-51615, 50381-50561 and 50554-51519. Cluster analysis of Polish oat landraces based on ISSR's polymorphism showed no grouping of accessions according to their collection region; for example accessions, which have the highest coefficient of similarity and are grouped closest to each other, were collected in various locations and in different decades. Grouping of landraces in accordance with botanical variety was also faintly visible on the dendrogram. However, based on it, the linkage between the clusters and the color of lemma could be seen. In the first, from the top, cluster mainly the yellow lemma's accessions were grouped. In the second one accessions with white and yellow lemma were intermixed almost in equal proportion. The third cluster at the bottom, that showed the lowest internal affinity, was dominated by the white lemma accessions.
Mantel test

The Mantel test result, calculated for matrices of genetic and geographic distance, also confirmed somehow the UPGMA clustering. The value of $r$ coefficient $(r=0.029)$ indicated a faint or even no correlation between these two matrices (Table 4). A weak positive correlation was demonstrated between genetic distance and altitude $(r=0.240)$. Since the positive correlation between altitude and precipitation $(\mathrm{r}=0.92 ; p=0.05)$, and negative one between altitude and temperature $(-0.92 ; p=0.05)$ were very strong, a weak correlations between these two environmental factors and genetic distance were observed too. For details see Table 4.

\section{AMOVA}

Analysis of molecular variance (AMOVA) which was carried out for the ISSR data showed no significant differences between geographic regions $(\Phi P T=0.003 ; p>0.05)$. However, the analysis performed for the groups of accessions assigned based on the altitude of collection site has detected a small but statistically significant variation among the groups $(\Phi \mathrm{PT}=0.017 ; p<0.05)$. Also for groups designated under the two other environmental factors, i.e. average annual temperature and precipitation in the collection sites AMOVA demonstrated the existence of small variation between the groups $(\Phi P T=0.047$, $p<0,05 ; \quad$ ФРТ $=0.037, \quad p<0.05$ respectively). These results confirm the Mantel's test. Further analysis, in which grouping was based on the color of lemma, confirmed noticeable clustering on UPGMA dendrogram $(\Phi \mathrm{PT}=0.039, p<0.05)$. At the same time no significant variation between the two groups of accessions with uni- and equilateral panicle was observed. AMOVA was not carried out for a set of botanical varieties. This resulted from described above the heterogeneity of studied accessions. The $\chi^{2}$ test was carried out to verify if accessions heterogeneity depended on geographic region or altitude. Both of these hypotheses were rejected. However, on the basis of the Fig. 1 some trend could be notice that the more homogeneous accessions were collected on the east of the country. 
Fig. 3 Scatterplot of principal coordinates 1 and 2 of 67 oat landraces, based on Dice dissimilarity matrix. The numbers in the legend correspond to the number of clusters in the UPGMA dendrogram

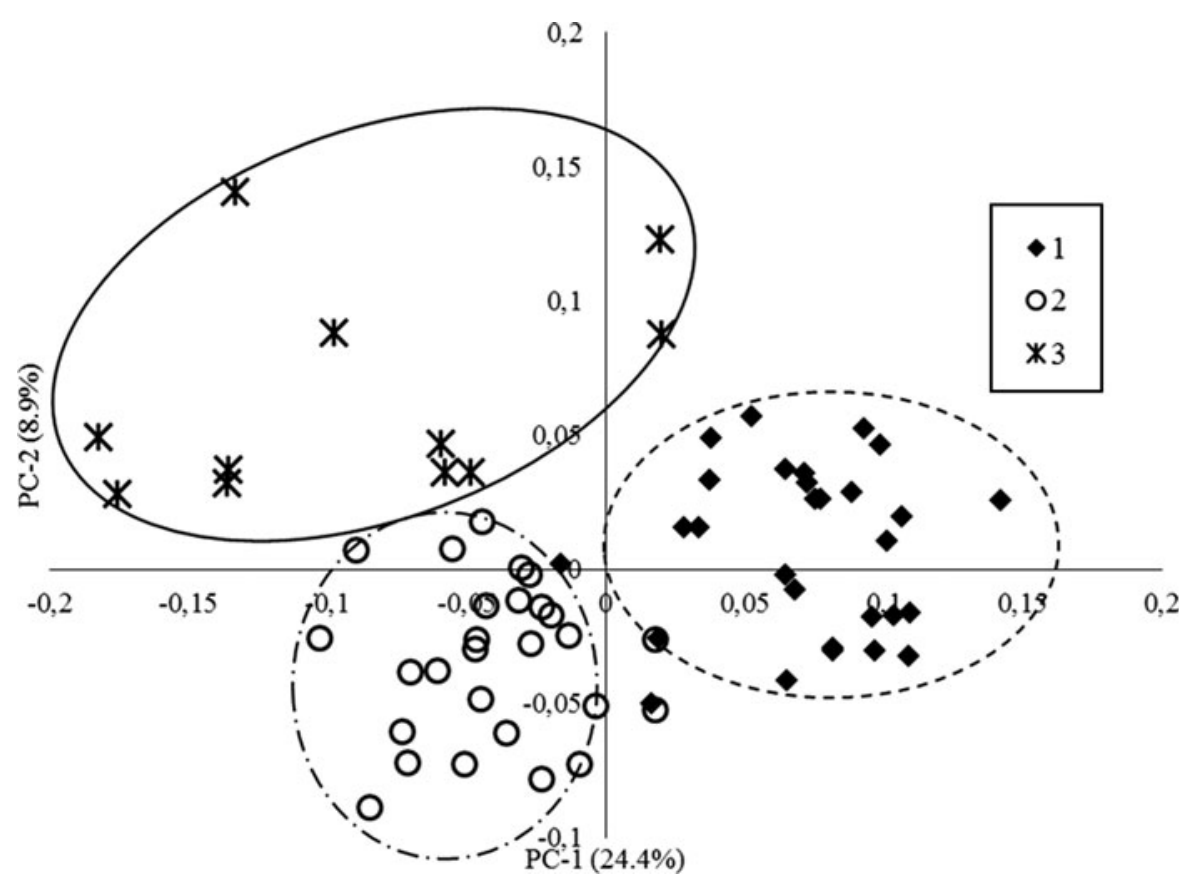

Principal coordinate analysis

The principal coordinate analysis (PCoA) was performed to confirm the structure and to acquire knowledge about the diversity of Polish oat landraces (Fig. 3). The first three principal components explained the total of $41.1 \%$ of ISSR variation (24.4, 8.9, and $7.8 \%$, respectively). The first axis, which accounted for $24.4 \%$ of the variance, separated the accessions which have been assigned to the first and second clusters by UPGMA. The second axis, accounted for $8.9 \%$ of the variance, could further place the landraces from the third cluster into another, the most diverse group. It is clear that results obtained by these two methods in an independent manner, complement each other.

\section{Discussion}

In the past half century, both the decrease of the number of grown cultivars and forms of oats, and the reduction in acreage occurred. From the perspective of genetic resources conservation both of these factors had negative impact on the number of in situ (on farm) genotypes. Therefore detailed insight into the ex situ collection has become so important, especially to determine the diversity of a gene pool stored in gene banks worldwide. It is crucial not only for effective gene bank management, but also for the further development of breeding. Different types of molecular markers are increasingly used to evaluate the genetic diversity of germplasm collections. The usefulness of ISSRs in this type of analysis has been confirmed for example in wheat, barley and sorghum (Sofalian et al. 2008; Fernández et al. 2002; Medraoui et al. 2007).

\section{ISSR informativeness}

In this paper, efficiency of ISSR was determined both as the amount of polymorphism and PIC (Polymorphic Information Content) coefficient. The average level of polymorphism, for the set of eight ISSR primers used in this study, was $59.3 \%$ which is comparable with bibliography data. Paczos-Grzeda $(2007,2009 a$, b) in the studies of various Avena species diversity, obtained 41.7, 44.2 and $70.9 \%$ of polymorphic fragments for A. sativa, A. fatua L. and A. sterilis L. respectively. ISSR markers have a reputation of being highly polymorphic; however, the publication cited above indicates that the participation of polymorphic fragments largely depends on the species, degree of differentiation of the tested materials and a set of primers. Medium or even low level of polymorphism 
seems to be specific to the A. sativa. Fu et al. (2003) in the analysis of genetic diversity of 96 Canadian oat cultivars obtained for AFLP $42.8 \%$ polymorphic fragments. Even lower level of polymorphism was reported by (Paczos-Grzęda 2004) i.e. 28.9 and $42.9 \%$ for RAPD and AFLP analysis of Polish oat cultivars. In contrast to Kaur et al. (2009), who reported a greater number of polymorphic fragments after amplification with the $5^{\prime}$ anchored di-nucleotide primers, in our study, there were no significant differences neither in quantity nor in the frequency of polymorphic products between $3^{\prime}$ or $5^{\prime}$ anchored primers. The average PIC value for the whole set of ISSR was rather low (0.20). This is a direct result of the presence of numerous fragments with a high (above 0.9) frequency. Similar values of PIC (0.21) were reported by Thomas and Bebeli (2010) for Aegilops species.

\section{Genetic diversity}

Three coefficients are now commonly used to evaluate genetic similarity: Dice (1945), Jaccard (1908) and SM. For each pair of accessions presented in this paper, all three coefficients were calculated, and then the analysis of correlation was performed. It has confirmed the presence of a strong positive correlation between the Dice, Jaccard and SM analysis results. Similar conclusions were presented by Thomas and Bebeli (2010). In connection with the fact that most of Avena genetic diversity studies based on Dice coefficient, the results were also processed that way. The obtained results indicated a relatively low diversity (0.09-0.37) of the common oat landraces collected on Polish territory. The genetic variability of Polish modern oat cultivars was even lower $(0.01-0.1)$ as reported by Paczos-Grzęda (2007) on the basis of ISSR data. The results obtained by RAPD for the same group of cultivars were almost identical i.e. $0.02-0.15$ (Paczos-Grzęda 2007). The multiplicity of available DNA polymorphism detection methods, associated with different regions of the genome, may cause sometimes huge variation in the value of genetic diversity coefficients. While the levels of the citied above Dice similarities for ISSR and RAPD markers were similar, whereas the AFLPs detected much greater diversity in Polish A. sativa cultivars i.e. similarity ranged from 0.381 to 0.869 (Chrząstek et al. 2006). The combined data of RAPD and AFLP for Polish oat cultivars showed also genetic similarity at the comparable level 0.35-0.88 (Paczos-Grzęda 2004). Furthermore, the genetic similarity calculated based on molecular markers was not significantly correlated with coefficient of parentage estimated on the basis of pedigree (Paczos-Grzęda 2004, 2007).

Previous studies have shown a very weak relationship between morphological variability and DNA polymorphism detected with AFLP markers in Polish oat landraces (Nowosielska and Nowosielski 2008). ISSR markers were more compatible with morphological data then AFLP. For example, both analysis showed that the accessions 52351, 51604 and 50902 had lower affinity to the remaining landraces. Whereas as in previous studies these accessions, collected in the same location showed genetic distinctiveness, however homology of morphological traits was observed.

Analysis of molecular variation (AMOVA) showed that there were no significant differences within dedicated geographical regions. At the same time it indicated that the altitude of collection site had significant effect on the genetic differentiation of the accessions. This analysis also demonstrated the presence of molecular variance in the groups that had been designated on the basis of average annual temperature and precipitation. This was a direct result of strict correlation between this two environmental conditions and altitude. These results were further confirmed by the Mantel test, which showed weak positive correlations between genetic distance and altitude, average annual temperature and precipitation. Previously Nowosielska and Nowosielski (2008) observed also a relationship of glabrous basal part of the primary grain with these two environmental factors. This indicated the existence of environmental conditions impact on the formation of Polish landraces. However, based on the performed research, determination of the nature of the generated changes was impossible. For this purpose, the level of genetic diversity within each accession should be known, and therefore conducting an analysis of individuals will be necessary.

AMOVA also indicated the presence of variance between groups designated by the color of lemma. White lemma accessions were characterized also by the highest genetic distinctiveness, as indicated by UPGMA and PCoA analysis. Separated with these two methods third group of accessions was composed almost entirely of white lemma plants which were collected at relatively high altitude. White lemma oats were characterized by lower resistance to drought than 
the yellow lemma ones (Lewicki and Mazurek 1967). This may explain why white lemma landraces were collected mainly in mountain areas where the amount of annual precipitation is higher. The harsh climate of mountain regions could cause further increase in diversity of these accessions. Also in this group, accessions were observed which had been typed in previous studies as having a unique combination of morphological and genetic traits (Nowosielska and Nowosielski 2008).

The literature data indicate that examined so far the gene pool of $A$. sativa seems to be relatively narrow. Especially the cultivars which were bred in Europe had significantly lower genetic diversity than those obtained in breeding programs in North and South America. Only a few cultivars from Eastern Europe exhibited some distinctiveness (Achleitner et al. 2008). Analysis of genetic variation carried out for 670 accessions from 79 countries indicated that the highest level of variation occurred within those obtained from Russia and the Unites States, while, the accessions from Mediterranean basin were characterized by the highest genetic distinctiveness (Fu et al. 2005). The analysis of genetic diversity within a world collection of cultivated hexaploid oat based on qualitative morphological characters of the 10,105 accessions from 85 countries showed the presence of 118 morphological groups (Diederichsen 2008). In these studies, the region of Eastern Europe was characterized as the third largest in terms of diversity. The accessions from the Poland were divided into 15 groups, which indicated that Polish collection was the most varied in the region (Diederichsen 2008). In the presented study within the 67 accessions there were five botanical varieties according to the classification by Rodionova et al. (1994). However, if we applied the grouping criteria set out by Diederichsen (2008) that number of groups would decrease to three. The low level of morphological diversity could explain somehow the high genetic similarity of test accessions.

Due to an intensive exchange of breeding materials for over the century, currently it is almost impossible to refer unambiguously genetic differentiation to the place of accession origin (Diederichsen 2009). However, the author pointed out, that the differences in the morphological traits between countries were observed. On the other hand, the AFLP analysis indicated that most of the variation was located within the country (Fu et al. 2005). The difference of opinion may be due to the fact that the morphological traits are controlled by several loci, which in the vastness of information generated by molecular markers are unnoticeable (Diederichsen 2009). Results of both Fu et al. (2003) and Leisova et al. (2007) indicated that breeding programs have had a significant impact on the decrease of common oat genetic diversity. Both of them also suggested the need to expand the gene pool of $A$. sativa.

In gene banks all over the world about 220,000 accessions of the genus Avena are preserved, of which the one-third is common oat. Polish oats collection, in the National Centre for Plant Genetic Resources, consists of about 2,500 accessions. More than $80 \%$ of them belong to the species A. sativa. Only 136 accessions have the landrace or traditional cultivar status and out of them 91 have been collected in Poland. Polish landraces collection is dominated by accession with yellow lemma. There are also relatively numerous accessions with white lemma color. However, in the territory of Poland actually no oats with dark color of lemma were collected (gray-1, brown-1). Grains with dark lemma appeared in several heterogeneous accessions. This is probably due to the farmers' preferences and the lack of cultivation tradition of oats with dark lemma. Diederichsen (2008) also observed a lower than expected frequency of dark lemma accessions in Eastern Europe.

There are different opinions on the potential utility of oat landraces in breeding programs. A comprehensive study of the Nordic Gene Banks oat collections indicated that landraces could be a valuable source of genetic variation that has been lost by modern breeding. Specially unique and rare alleles that occurred in old landraces did not appear in modern commercial cultivars (Nersting et al. 2006). While Fu et al. (2005) pointed out that the genetic variability of oat landraces oats is not greater than the breeding materials. But considering the evident impact of local climatic conditions on the genetic distinctiveness of Polish landraces and the discussed above potential inconsistence of morphological and molecular data, utility of these accessions in the Polish breeding programs is worth of consideration.

Acknowledgments The authors would like to express their utmost gratitude to Zofia Bulińska-Radomska, head of National Centre for Plant Genetic Resources, IHAR-PIB, who created the capacity to perform the analysis presented in this paper. Also heartfelt thanks to Bogusław Łapiński, for his constructive remarks. 
Open Access This article is distributed under the terms of the Creative Commons Attribution License which permits any use, distribution, and reproduction in any medium, provided the original author(s) and the source are credited.

\section{References}

Achleitner A, Tinker N, Zechner E, Buerstmayr H (2008) Genetic diversity among oat varieties of worldwide origin and associations of AFLP markers with quantitative traits. Theor Appl Genet 117:1041-1053. doi:10.1007/s00122008-0843-y

Blair MW, Panaud O, McCouch SR (1999) Inter-simple sequence repeat (ISSR) amplification for analysis of microsatellite motif frequency and fingerprinting in rice (Oryza sativa L.). Theor Appl Genet 98:780-792. doi:10.1007/s001220051135

Chrząstek M, Paczos-Grzęda E, Kruk K (2006) Ocena zróżnicowania genetycznego polskich odmian owsa (Avena sativa L.). Acta Agrophy. 8:319-326

Dice L (1945) Measures of the amount of ecologic association between species. Ecol. 26:297-302

Diederichsen A (2008) Assessments of genetic diversity within a world collection of cultivated hexaploid oat (Avena sativa L.) based on qualitative morphological characters. Genet Resour Crop Evol 55:419-440. doi:10.1007/s10722-0079249-y

Diederichsen A (2009) Duplication assessments in Nordic Avena sativa accessions at the Canadian national genebank. Genet Resour Crop Evol 56:587-597. doi:10.1007/ s10722-008-9388-9

Excoffier L, Smouse P, Quattro J (1992) Analysis of molecular variance inferred from metric distances among DNA haplotypes: application to human mitochondrial DNA restriction data. Genet. 131:479-491

Fernández M, Figueiras A, Benito C (2002) The use of ISSR and RAPD markers for detecting DNA polymorphism, genotype identification and genetic diversity among barley cultivars with known origin. Theor Appl Genet 104:845-851. doi:10.1007/s00122-001-0848-2

Fu Y, Peterson G, Scoles G, Rossnagel B, Schoen D, Richards K (2003) Allelic diversity changes in 96 Canadian oat cultivars released from 1886 to 2001. Crop Sci 43:1989-1995

Fu Y, Peterson G, Williams D, Richards K, Fetch J (2005) Patterns of AFLP variation in a core subset of cultivated hexaploid oat germplasm. Theor Appl Genet 111:530-539. doi:10.1007/s00122-005-2044-2

Gupta M, Chyi Y-S, Romero-Severson J, Owen J (1994) Amplification of DNA markers from evolutionarily diverse genomes using single primers of simple-sequence repeats. Theor Appl Genet 89:998-1006. doi:10.1007/BF0022 4530

Jaccard P (1908) Nouvelles recherches sur la distribution florale. Bul. Soc. Vaudoise Sci. Nat. 44:223-270

Kaur B, Wadhwani C, Charaya P, Malik C (2009) Markers used in diversity analysis. In: Malik CP, Wadhwani C, Kaur B (eds) Crop breeding and biotechnology pointer publishers. Jaipur, India, pp 65-107
Leisova L, Kucera L, Dotlacil L (2007) Genetic resources of barley and oat characterised by microsatellites. Czech J. Genet. Plant Breed. 43:97-104

Lewicki S, Mazurek J (1967) Owies Państwowe Wydawnictwo Rolnicze i Leśne, Warszawa

Loskutov I (2013) Intraspecific systematics of genus Avena L. http://vir.nw.ru/avena/syst.htm. Accessed 13 Jan 2013

Mantel N (1967) The detection of disease clustering and a generalized regression approach. Cancer Res 27:209220

Medraoui L, Ater M, Benlhabib O, Msikine D, Filali-Maltouf A (2007) Evaluation of genetic variability of sorghum (Sorghum bicolor L. Moench) in northwestern Morocco by ISSR and RAPD markers. C R Biol. 330:789-797. doi:10.1016/j.crvi.2007.08.005

Meyer W, Mitchell G, Freedman E, Vilgays R (1993) Hybridization probes for conventional DNA fingerprinting used as single primers in the polymerase chain reaction to distinguish strains of Cryptococcus neoformans. J Clin Microbiol 31:2274-2280

Moreno S, Martín J, Ortiz J (1998) Inter-simple sequence repeats PCR for characterization of closely related grapevine germplasm. Euphytica 101:117-125. doi:10.1023/A:10183 79805873

Nersting L, Andersen S, von Bothmer R, Gullord M, Jørgensen R (2006) Morphological and molecular diversity of Nordic oat through one hundred years of breeding. Euphytica 150:327-337. doi:10.1007/s10681-006-9116-5

Nowosielska D (2006) Różnorodność genotypowa i morfologiczna odmian i populacji miejscowych owsa (Avena sativa L.) uprawianych w Polsce

Nowosielska D, Nowosielski J (2008) Morphological diversity and DNA polymorphism of common oat (Avena sativa L.) landraces cultivated in Poland. Plant Breed. Seed Sci. 58:11-22

Paczos-Grzęda E (2004) Pedigree, RAPD and simplified AFLPbased assessment of genetic relationships among Avena sativa L. cultivars. Euphytica 138:13-22. doi:10.1023/ B:EUPH.0000047055.99322.7a

Paczos-Grzęda E (2007) Wykorzystanie metod ISSR i RAPD oraz analizy rodowodów do oceny podobieństwa międzyodmianowego Avena sativa. Zesz. Probl. Post. Nauk Rol. 517:547-558

Paczos-Grzęda E, Chrząstek M, Okoń S, Grądzielewska A, Miazga D (2009a) Zastosowanie markerów ISSR do analizy wewnątrzgatunkowego podobieństwa genetycznego Avena sterilis L. Biul. Inst. Hod. Rośl. 252:215-223

Paczos-Grzęda E, Kruk K, Okoń S (2009b) Ocena wewnątrzgatunkowego podobieństwa genetycznego Avena fatua L. w oparciu o polimorfizm DNA. Biul. Inst. Hod. Rośl. 253:235-243

Page R (1996) TREEVIEW: an application to display phylogenetic trees on personal computers. Comput Appl Biosci 12:357-358

Peakall R, Smouse P (2006) GENALEX 6: genetic analysis in Excel. Population genetic software for teaching and research. Mol Ecol Notes 6:288-295. doi:10.1111/j.14718286.2005.01155.x

Pujar S, Tamhankar SA, Gupta VS, Rao VS, Ranjekar PK (2002) Diversity analysis of Indian tetraploid wheat using intersimple sequence repeat markers reveals their 
superiority over random amplified polymorphic DNA markers. Biochem Genet 40:63-69. doi:10.1023/A:1014 593206886

Rodionova NA, Soldatov VN, Merezhko VE, Jarosh NP, Kobyljanskij VL (1994) Flora of cultivated plants, vol 2, Part 3, Oat. Kolos, Moscow

Roldan-Ruiz I, Dendauw J, Van Bockstaele E, Depicker A, De Loose M (2000) AFLP markers reveal high polymorphic rates in ryegrasses (Lolium spp.). Mol. Breed. 6:125-134. doi:10.1023/A:1009680614564

Schlüter P, Harris S (2006) Analysis of multilocus fingerprinting data sets containing missing data. Mol Ecol Notes 6:569-572. doi:10.1111/j.1471-8286.2006.01225.x

Shen J, Ding X, Liu D, Ding G, He J, Li X, Tang F, Chu B (2006) Intersimple sequence repeats (ISSR) molecular fingerprinting markers for authenticating populations of Dendrobium officinale KIMURA et MIGO. Biol Pharm Bull 29:420-422. doi:10.1248/bpb.29.420

Sofalian O, Chaparzadeh N, Javanmard A, Hejazi MS (2008) Study the genetic diversity of wheat landraces from northwest of Iran based on ISSR molecular markers. Int. J. Agri. Biol. 10:465-468

Tanyolac B (2003) Inter-simple sequence repeat (ISSR) and RAPD variation among wild barley (Hordeum vulgare subsp. spontaneum) populations from west Turkey. Genet Resour Crop Evol 50:611-614. doi:10.1023/A:1024412814757

Thomas K, Bebeli P (2010) Genetic diversity of Greek Aegilops species using different types of nuclear genome markers. Mol Phylogenet Evol 56:951-961. doi:10.1016/j.ympev. 2010.04.041

Tsumura Y, Ohba K, Strauss S (1996) Diversity and inheritance of inter-simple sequence repeat polymorphisms in Douglasfir (Pseudotsuga menziesii) and sugi (Cryptomeria japonica). Theor Appl Genet 92:40-45. doi:10.1007/ BF00222949

Virk PS, Zhu J, Newbury HJ, Bryan GJ, Jackson MT, FordLloyd BV (2000) Effectiveness of different classes of molecular marker for classifying and revealing variation in rice (Oryza sativa) germplasm. Euphytica 112:275-284. doi:10.1023/A:1003952720758

Wu K, Jones R, Danneberger L, Scolnik P (1994) Detection of microsatellite polymorphisms without cloning. Nucleic Acids Res 22:3257-3258. doi:10.1093/nar/22.15.3257

Zietkiewicz E, Rafalski A, Labuda D (1994) Genome fingerprinting by simple sequence repeat (SSR)-anchored polymerase chain reaction amplification. Genomics 20: 176-183 